\title{
PHOTOELECTRIC MEASUREMENT OF MELANO- PHORAL ACTIVITY OF FROG SKIN INDUCED IN VITRO
}

\author{
PAUL A. WRIGHT \\ Department of Zoology, University of Washington, Seatte, and the \\ Department of Zoology, University of Michigan
}

THIRTEEN FTGURES

Changes in dispersion or concentration of pigment within melanophores of vertebrates have been studied chiefly by the use of the microscope, and as a scale of measurement the melanophore index of Slome and Hogben ('28) has been adopted widely. This system has the disadvantage of being arbitrary and incapable of detecting slight movements of pigment which may well prove to be significant. Of several methods proposed to meet these difficulties, the photoelectric techniques of Hill et al. ('35) and Smith ('36) appear to be most practical and accurate. Hill and his associates measured photoelectrically the amount of light reflected from the dorsal surface of Fundulus as the fish adjusted to changing background. Smith's procedure differs from Hill's in that tabulations were made of changes in intensity of light transmitted through isolated scales of Tautoga. It is the purpose of the present paper to describe in detail a procedure (Wright, '46) for measuring by photoelectric means color changes in pieces of excised frog skin during and following treatment with pituitary suspensions.

\section{MATERIALS AND METHODS}

For sake of uniformity, only male frogs (Rana pipiens) weighing between 40 and $60 \mathrm{gm}$ were used. These animals 
were kept in a dark-walled container at room temperature so that the great majority of frogs were dark-adapted when selected for use. After pithing, the complete femoral skin was removed, placed in amphibian Ringer's solution (phosphate, bicarbonate buffered, glucose-free), and carefully cleaned of any bits of muscular or connective tissue. Preliminary tests had shown that the skin from this part of the leg was most suitable since it was of uniform thickness and devoid of the supporting ridges encountered in the dorsal integument. The pieces were then fastened securely, without stretching or undue pressure, between bakelite frames in which matched openings $(12.5 \mathrm{~mm} \times 38 \mathrm{~mm})$ had been cut. The outside dimensions $(39.5 \mathrm{~mm} \times 67 \mathrm{~mm})$ of these opaque frames were designed so that the plates could be inserted readily into the rectangular absorption cell of the Klett-Summerson phatoelectric colorimeter, the instrument used to measure activity of pigment cells. Since the colorimeter scale was divided into logarithmic units $(0-1000)$, and because of the difficulty involved in averaging logarithmic values, it seemed advisable to convert the colorimeter readings into antilogarithms. In doing this, the scale reading was considered the mantissa and a characteristic of 1 was assumed; thus, all converted values fell between 12.59 and $24.49 .^{1}$

When readings were not being taken, it was found convenient to keep skin preparations in Petri dishes $(100 \mathrm{~mm}$ diameter) submerged in $50 \mathrm{~cm}^{3}$ of Ringer's solution or of Ringer-pituitary suspension. Whole pituitary glands from male frogs served as the source of the melanophore-darkening hormone (intermedin). The tissue was finely macerated in a porcelain mortar, taken up in the desired volume of Ringer's fluid, and the various concentrations of the test suspensions secured by dilution. All experiments were performed at room temperature $\left(22^{\circ}-24^{\circ} \mathrm{C}\right.$. $)$.

\footnotetext{
- The industrial model of the colorimeter is equipped with a ground glass shutter which decreases the differential between the 2 photoelectric cells. This device was used in all experiments since it brought the readings into a more workable range.
} 


\section{EXPERIMENTAI PROCEDURES AND RESULTS}

To perform the steps described above, i.e., to remove 2 pieces of skin, clean, and suspend them between bakelite frames, requires from 20 to 25 minutes. During this period the pigment in melanophores begins to concentrate, so that the first reading (taken approximately 30 minutes after the skin is removed from the animal) is considerably lower than would be recorded if it were possible to make a reading at the time skin is excised. Melanin concentration continues during the next 30 minutes (fig. 1), but by the end of this time melanophores are fully punctate and will remain so indefinitely,

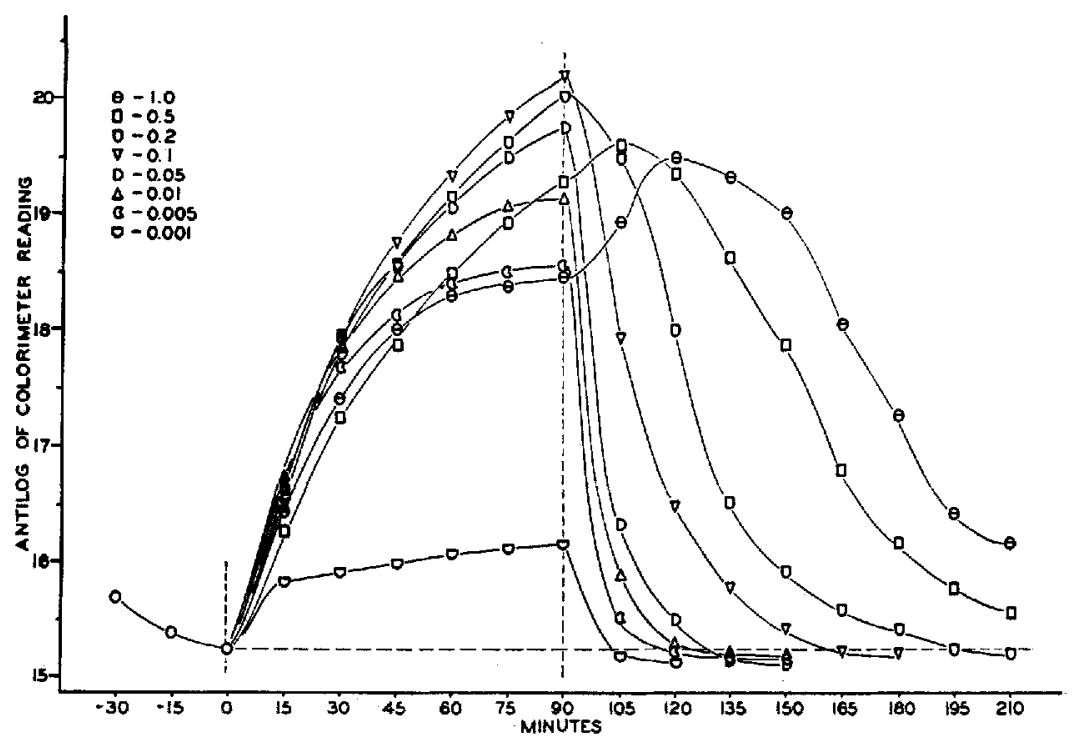

Fig. 1 Results of 64 experiments in which pieces of excised frog skin mounted in bakelite frames were exposed for 90 minutes to pituitary suspensions ranging in concentration from one-thousandth to 1 pituitary gland in $50 \mathrm{~cm}^{3}$ Ringer's solution. Dispersion and concentration of melanophore pigment were followed in a photoelectric colorimeter and the readings obtained have been converted to antilogarithms and averaged. The majority of frogs were dark-adapted when selected for use. Curve illustrated between -30 and 0 minutes represents average readings for the 64 skins up to the time of exposure to pituitary suspensions. After 90 minutes contact with pituitary suspensions, skins were replaced in Ringer's solution which was changed every 30 minutes until the end of the experiment. Dates: February to August. Temperature: $22^{\circ}-24^{\circ} \mathrm{C}$. 
as determined repeatedly in control tests, if the skin is kept in Ringer's fluid.

Addition of macerated pituitary substance or extract to the medium causes dispersion of pigment to begin immediately, reducing light transmission and resulting in higher colorimeter readings. Rate and extent of response varies considerably, however, depending upon the amount of intermedin available, as shown by a total of 64 experiments in which pituitary preparations ranging in concentration from one-thousandth to 1 gland in $50 \mathrm{~cm}^{3}$ Ringer's solution were used (fig. 1). In these tests, skins were placed in Ringerpituitary suspensions for 90 minutes during which time readings were taken in the colorimeter at 15-minute intervals. Results show that darkening of the skins during this 90-minute period becomes more intense as the concentration of pituitary material approaches one-tenth of a gland in $50 \mathrm{~cm}^{3}$ of fluid, but response is apparently maximal at or near this point. Further increase beyond this amount, up to a concentration of 1 macerated gland in $50 \mathrm{~cm}^{3}$, at least, results in a noticeably submaximal reaction during the 90 minutes.

Following pituitary treatment, skins were replaced in $50 \mathrm{~cm}^{3}$ Ringer's solution which was changed every 30 minutes until the end of the experiment. It will be noted that after exposure to suspensions containing one-half and one triturated pituitary gland, skins continue to darken for a time upon removal to Ringer's fluid and then blanch. Following contact with suspensions containing two-tenths pituitary gland or less, however, blanching begins soon after the skins are washed in Ringer's solution and is not preceded by further darkening. Recovery of the preparations, i.e., return of melanophores to a fully punctate condition, is readily traceable when these more dilute suspensions are used. On the other hand, the time required for complete blanching after immersion in suspensions containing one-half and one gland is extremely variable, in fact, so much so that significant averages were not obtained. 
A series of photomicrographs were taken to compare the colorimeter readings and the actual condition of melanophores during the course of an experiment. A concentration of onetenth pituitary gland in $50 \mathrm{~cm}^{3}$ Ringer's fluid was chosen for this study since response under these conditions was maximal and recovery relatively rapid. Results (plates 1 and 2 ) seem to indicate a very close correspondence between colorimeter values and the state of dispersion or concentration of pigment, and attach further significance to photoelectric technique as a method of melanophore study.

\section{DISCUSSION}

The chief criticisms of the photoelectric means of studying melanophore activity have been (1) that the sum total of all chromatophoral pigment changes is measured without reference to activity of any particular color cell (Wykes, '37; Neill, '40); and (2) that scale readings may not provide "an accurate estimate of the degree of expansion of the melanophores at various stages of their response"' (Wykes, '37), i.e., a "low" reading might indicate a melanophore index of 1,2 , or some intermediate value. It cannot be contested that the photoelectric method records pigment changes of other chromatophores, if and when they occur, as well as those of melanophores. But since it seems likely that the chief means by which many fishes and amphibians change their color is through concentration or dispersion of melanin alone (Abramowitz, '39; Parker, '43), it appears that photoelectric measurement could be accepted as accurately indicating melanophore activity. If subsequent spectrophotometric studies show that chromatophore changes other than those of melanophores are concerned in the chromatics of Rana pipiens, or if a distinct differential activity of chromatophores is ascertained, the latter statement will very likely be discredited. In reply to the second criticism, it should be pointed out that it is possible to establish by microscopic examination or by a series of photomicrographs (plates 1 and 2) a correlation between photoelectric values and the actual state of melanin dispersion. 
Since correspondence has been shown to exist and since slight pigment alterations cause very definite differences in colorimeter readings, it would appear that a system of measurement has been found which is a little more meaningful and refined than the 5-point melanophore index series of Slome and Hogben. As Parker ('43) has pointed out, the melanophore index consists of arbitrary units assigned for convenience in describing the state of dispersion of melanin. Even the authors of the system point out (Slome and Hogben, '29) that the numbers used may bear no mathematical significance, and are not to be construed as indicating, for example, that a skin whose melanophores show an index of 2 is twice as dark as one whose melanophores are completely punctate, i.e., index 1. Furthermore, the amount of dispersion seen between index 1 and 2 may not be identical to that occurring between 2 and 3 , etc. There is some question, then, what mean ing should be attached to averages of melanophore indices and to plottings of them in graph-like form. Colorimeter readings, on the other hand, are directly proportional to the amount of light transmitted, and the intervals shown in figure 1 are mathematically true.

The question of the applicability of this technique for the assay of intermedin has been raised and is being investigated (Frieden and Fishbein, '47). Certainly results presented here are not sufficient to allow one to state that an assay procedure could or could not be devised along these lines. A very few control experiments have been carried out (using acetyl choline, $10^{-4}$ and $10^{-5}$, with and without eserine, $10^{-4}$ and $10^{-5}$, and blood serum, $0.5 \%$, from lightadapted frogs) with entirely negative results. It is commonly admitted that certain drugs and alkaloids may cause darkening of the skin in intact frogs, and Trendelenburg ('26) and Jores ('33) report that the response of isolated frog' skin (Rana temporaria) is unspecific. Abramowitz ('40) reremarks that "the results on isolated tissue cannot be accepted unless osmotic, ionic, $\mathrm{pH}$ conditions, etc., are rigorously controlled." Whether this technique will find extensive use as an 
assay method is therefore debatable. There appears to be no ojection, however, to its use in the study of physiology of melanophores and in comparing effectiveness of substances known to contain intermedin.

An analysis of results presented above reveals several points of interest. It will be noted that a concentration of one-tenth pituitary gland in $50 \mathrm{~cm}^{3}$ Ringer causes a maximal response during 90-minute exposure and that a submaximal reaction occurs whether the suspension used is either more or less concentrated. This observation recalls to mind results of in vitro experiments on frog ovary (Wright, '45) in which the greatest percentage of ovulation was obtained when suspensions of one-sixteenth or one-eighth of a macerated pituitary gland in $10 \mathrm{~cm}^{3}$ Ringer were employed; more concentrated or dilute suspensions were less effective. Explanations of these findings in either case are not immediately apparent. It is not known what significance, if any, should be attached to the fact that skins subjected to suspensions containing one-half and one pituitary gland continue to darken for a time following removal to Ringer's fluid. This phenomenon suggests the possibility that a very concentrated pituitary suspension is partially inhibitory, but more extensive investigation may reveal a more plausible answer. The most striking observation is found in the relationship between concentration of the pituitary suspension and length of time required for skins to blanch following treatment. It may be accurately stated that a direct relationship between amount of pituitary substance in suspension and extent of reaction does exist.

Administration of adrenalin to frogs has long been known to bring about rapid blanching. It is not surprising, then, to find that this hormone markedly alters the course of reaction produced by pituitary extracts. Results of experiments using adrenalin will be reported in a subsequent publication.

\section{SUMMARY}

1. A method is described for photoelectric estimation of pigment changes in melanophores of excised frog skin in vitro. 
Pieces of skin from the thigh are placed in bakelite frames which are inserted readily into rectangular absorption cells of a photoelectric colorimeter, and pigment migration is detected by variation in amount of light transmitted through $4.75 \mathrm{~cm}^{2}$ of integument.

2. Within 1 hour after the skin is removed from darkadapted animals, melanophores are fully punctate and remain in this condition as long as preparations are kept in Ringer's solution.

3. Addition of macerated pituitary suspension causes dispersion of melanin to begin immediately, but the extent of reaction is dependent upon the concentration of pituitary substance in the medium, maximal response being obtained when the equivalent of one-tenth pituitary gland in $50 \mathrm{~cm}^{3}$ Ringer's solution is used.

4. It is possible to distinguish between suspensions containing the equivalents of five-thousandths and one-thousandth tuiturated pituitary gland in $50 \mathrm{~cm}^{3}$ of Ringer's solution, the former producing a response approximately $375 \%$ greater than the latter.

5. The time required for complete concentration of melanin following exposure to pituitary suspensions is roughly proportional to the potency of the suspensions employed.

6. A series of photomicrographs are presented correlating colorimeter readings with the actual condition of melanophore pigment.

\section{LITERATURE CITED}

Abramowitz, A. A. 1939 Color changes in animals. Tabulae Biologicae, 17 : $267-337$.

1940 A now method for the biological assay of intermedin. J. Pharm. and Exp. Therap., 69: 156-164.

FRIEden, E. H., AND .J. W. FISHLEIN 1947 A rapid bioassay for intermedin. Some properties of intermedin. Abstract of Papers, 112th Meeting, Am. Chem. Soc., New York, N. Y., September 15-19, 1947, p. 24 C.

Hull, A. V., J. L. Parkinson and D. Y. Solandt 1935 Photoelectric records of the colour change in Fundulus heteroclitus. J. Exp. Biol., 18: 397-399.

JoRes, A. 1933 Untersuchung über das Melanophorenhormon und seinen Nachweis in mensehlichen Blut. Zeitschr. f. die Ges. Exp. Med., 87 : 266-282.

NEILL, R. M. 1940 On the existence of two types of chromatic belariour in teleostean fishes. J. Exp. Biol., 17: 74-94. 
PARTER, G. H. 1943 Methods of estimating the effects of melanophore changes on animal coloration. Biol. Bull., Woods Hole, 84: 273-284.

Slome, D., AND L. Hogran 1928 The chromatic funetion in Xenopns laevis. So. Afr. J. Sci., 25: 329-335.

1929 The time factor in the chromatic responses of Xenopus laevis. Trans. Royal Soe. So. Afr., 17: 141-150.

Sмгтв, D. C. 1936 A method for recording chromatophore pulsations in isolated fish scales by means of a photoelectric cell. J. Cell. and Comp. Physiol., $8: 83-87$.

Trendementur, P. 1926 Weitere Versuche über den Gehalt des Liquor cerebrospinalis an wirksamen Substanzen des Hypophysen hinterlappens. Arch. f. Exp. Path, und Pharm., 174: 255-261.

WRIGHT, P. A. 1945 Factors affecting in vitro ovulation in the frog. J. Exp. Zool., 100: $565-575$.

1946 Response of the melanophores of frog skin to pituitary substances in vitro. Anat. Rec., $96: 540-541$.

Wykes, U. 1937 The photic control of pigmentary responses in teleost fishes. J. Exp. Biol, 14: 79-86. 


\section{PLATE 1}

EXPLANATION OF FIGURES

Photomicrographs of the same group of melanophores in a pice of excised frog skin taken at successive 15-minute intervals during and following exposure to a suspension of one-tenth triturated frog pituitary gland in $50 \mathrm{~cm}^{3}$ Ringer's solution. Because of the necessity of removing the skin from the medium for frequent photographing, a graphic representation of the solorimeter readings obtained in this experiment does not conform exactly to that of the response of other skins to one-tenth pituitary gland (fig. 1). Photomicrographs $\times 210$. Angust 6, 1946 .

2 Punctate melanophores at the time of addition of pituitary suspension. Colorimeter reading 201 .

3 Fifteen minutes after skin is placed in pituitary suspension. Colorimeter reading 223 .

4. Thirty minutes after figure 2. Colorimeter reading 254.

5 Forty-five minutes after figure 2. Colorimeter reading 269.

6 Sixty minutes after figure 2. Colorimeter reading 282.

7 Seventy-five minutes after figure 2. Colorimeter reading 285. 

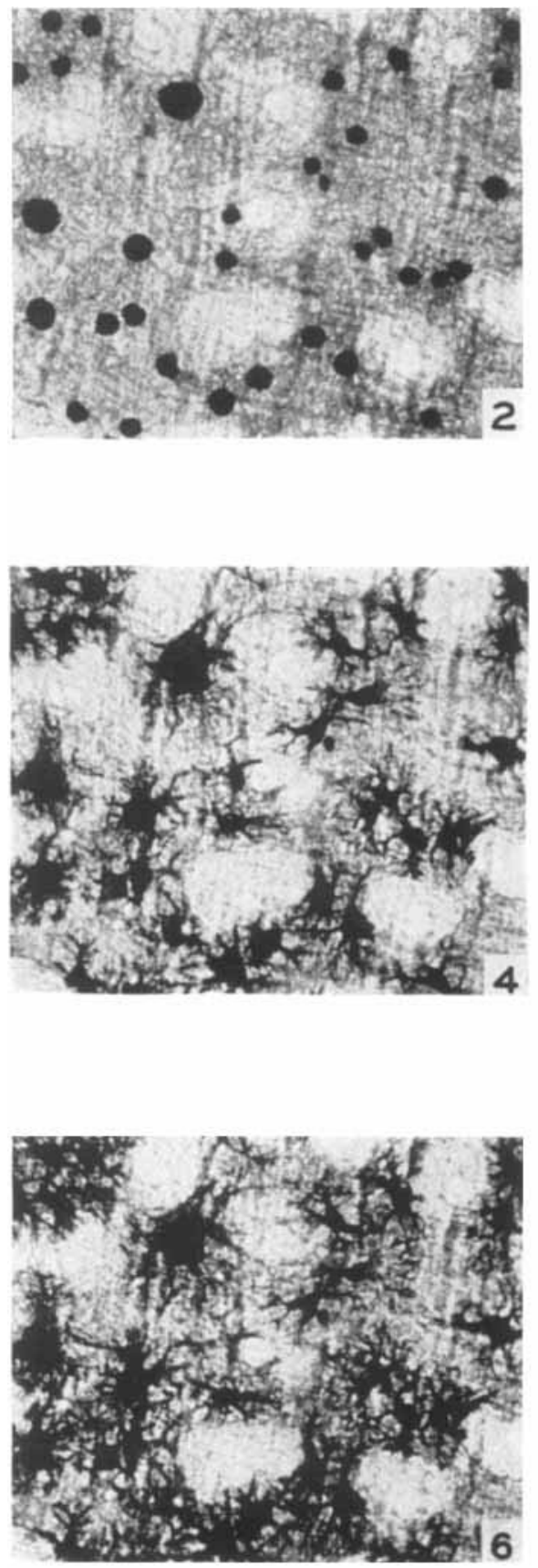
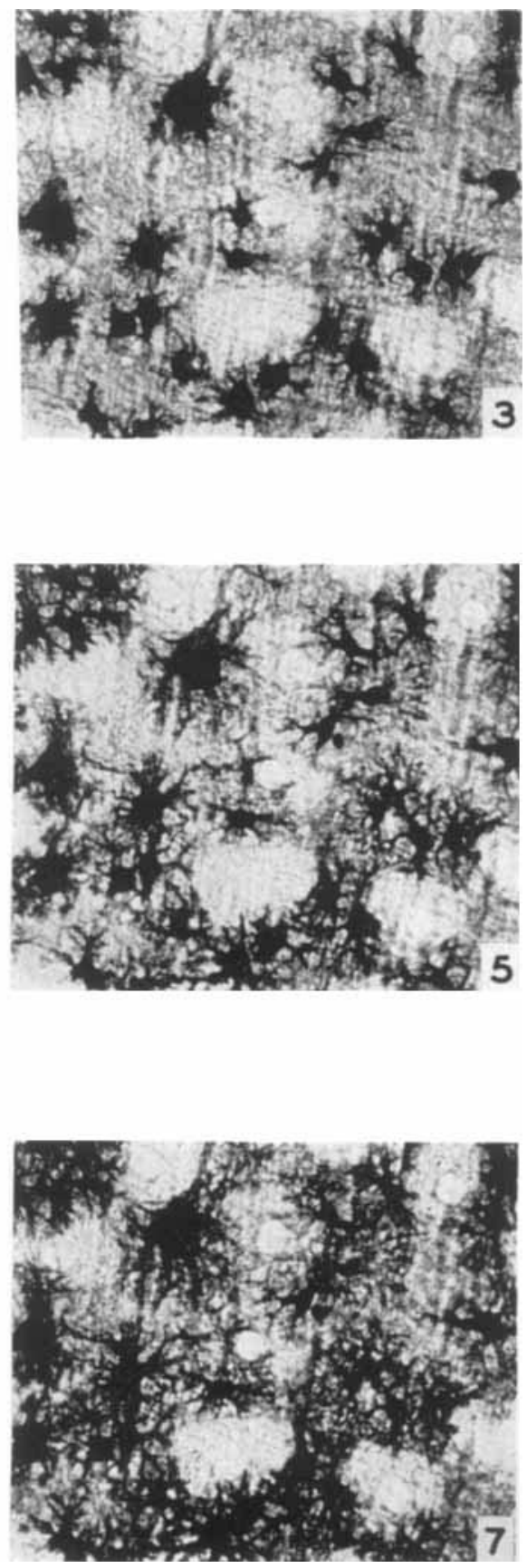


\section{PLATE 2}

\section{EXPLANATTON OF FIGUKES}

8 Xinety minutes after figure 2. Colorimeter reading 294. Skin replaced in Ringer's solution.

9 Fifteen minutes after figure 8. Colorimeter reading 282. Note 2 melanophores in extreme upper right.

10 Thirty minutes after figure 8. Colorimeter reading 252.

11 Forty-five minutes after figure 8. Colorimeter reading 298.

12 Sixty minutes after figure 8. Colorimeter reading 208.

13 Seventy-five minutes after figure 8. Melanophores punctate. Colorimeter reading 203. Compare figure 2. 

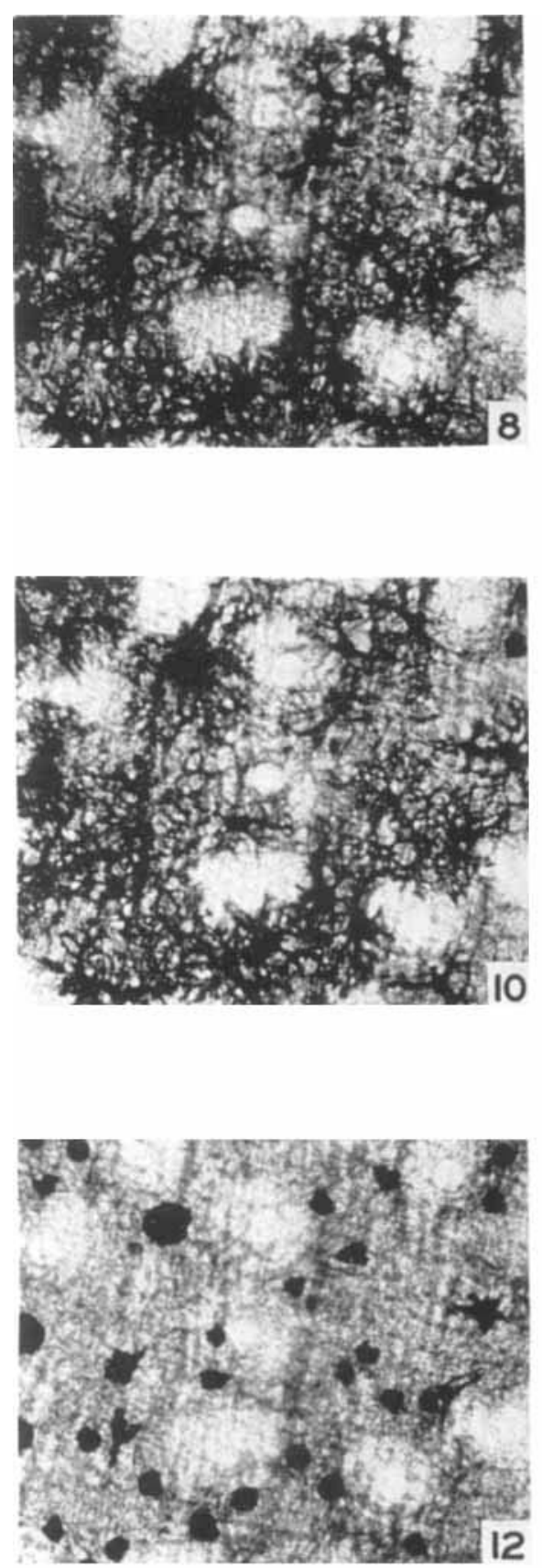
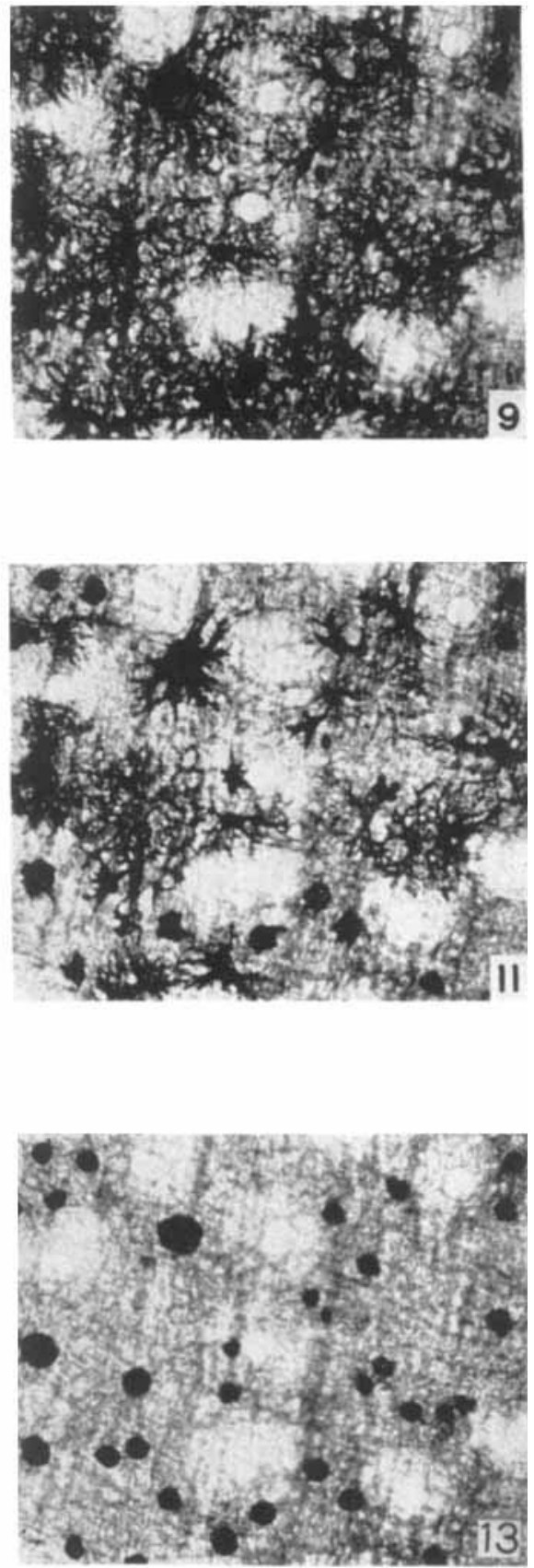